\title{
Eduardo Barrios (1884-1963)
}

$\mathrm{E}$ L día I $_{3}$ de septiembre de $x_{9} 63$ ha fallecido en Santiago, en edad muy avanzada, Eduardo Barrios, ilustre escritor chileno a quien se había otorgado, en r948, el Premio Nacional de Literatura. Según dicen quienes le vieron en sus últimos días, la muerte fue apoderándose gradualmente de su organismo, sin ocasionarle especial sufrimiento. Se apagó poquito a poco. En los meses finales de su existencia apenas hablaba ya, pues todo esfuerzo le ocasionaba enorme fatiga, si bien invitara a sus nietos a que le contaran sus cosas, y al llevarlos a sus brazos les dejaba jugar libremente con sus barbas. Tal fue su fin, acariciado por el amor de los suyos.

Hoy que ha muerto, tenemos derechos a preguntarnos qué nos deja. Bien. Hagamos una rápida visita a las bibliotecas universitarias de los Estados Unidos, y allí veremos casi todos sus libros, algunos traducidos, otros en el español original en que fueron escritos. Pasemos de largo y veamos las librerías en Buenos Aires, en México, en Bogotá, en Lima. También está allí Barrios, representado en libros editados y vueltos a editar, no ya en talleres impresores de Chile, que no se destinan a este menester, sino en talleres argentinos o mexicanos, donde esa prosa gallarda y nítida se sabe ya que cuenta mercado. Nos deja, pues, en el extranjero una inconfundible estampa de escritor.

De otra parte, la crítica en aquellas naciones también le ha considerado, le respeta, le elogia, le exalta. No es desapoderado, hoy, decir que a Barrios se le juzga el más profundo psicólogo de la novela que ha florecido en la literatura hispanoamericana, pues tal juicio viene a ser sólo la síntesis de ensayos prohijados por gentes muy diversas. Alberto Zum Felde, por ejemplo, ilustre crítico uruguayo, en su Indice crítico de la Literatura Hispanoamericana: la Narrativa, ha escrito (p. 2I4): 
De los autores chilenos, el que más cerca está de la novela propiamente psicológica es Eduardo Barrios, cuya novela $U n$ perdido ofrece espécimen ejemplar de tal manera. La materia pictórica característica es abundante y exacta, y de un verismo típicamente realista; pero todo está allí como en el mundo externo del personaje, la realidad con la cual lucha y por la cual es, al fin, vencido. Este personaje pertenece a la especie de los idealistas abúlicos que fatalmente han de frustrarse y caer por su inadaptación a las duras condiciones de la realidad.

Esto con relación a $U n$ perdido, a un solo tema, a un personaje que llena el libro; cosa semejante cabe decir de otros, los cuales en conjunto forman toda una galería.

El novelista fue impenitente observador de la naturaleza humana, y a ella le ha exigido sus secretos. Los estudiosos de su obra descubren hoy en ésta la encarnación en seres reales, observados en la vida misma, de aquellos ejemplares típicos en que la ciencia de la psicología anormal descubre desviaciones antisociales, es decir, locos, semilocos, impulsivos frenéticos, soberbios, hombres en quienes el vivir es tempestuoso o solapado, extremos ambos que distan de convenir a la verdadera economía psicológica de la persona humana. Es decir, el novelista logra, por su sola intuición de escritor, descubrir en el ser que le sale al paso, en su amigo, en su camarada, en su pariente, los rasgos clínicos que le podrían dar entrada al estudio de los especialistas en anormalidades de la conducta. Esto es nuevo en las letras chilenas, y les da una dimensión distinta.

No se diga ya que al novelista chileno le falta aptitud para bucear en las almas de los hombres. Desde que la obra de Eduardo Barrios ha sido echada a rodar, una obligación nueva pesa sobre el novelista nacido en este suelo, y la novela exterior, vacía de implicaciones psicológicas, atenida a los solos hechos físicos, que pudo ser antes encantadora y en todo satisfactoria para el lector común, hoy no puede ya llenarnos igualmente el gusto. Bartios ha creado con su obra apetencias que antes no existían. El novelista que anhele ponerse a la altura que le traza Barrios, debe mirar al hombre por dentro, divisar en él los efectivos problemas de su comportación psicológica, y ponerse lealmente a la tarea de dar forma literaria viable a lo que alli, en esos rincones secretos, haya divisado o entrevisto.

La literatura chilena, en suma, es diferente a lo que antes fue desde que por ella pasó este robusto creador novelesco. 
A los críticos literarios chilenos aquejados de manía racista, podrá alguna vez recordárseles la existencia de Eduardo Barrios, a ver si aciertan en el diagnóstico. Su padre, chileno, casó en el Perú, durante la ocupación de Lima por el ejército triunfante en Chorrillos y Miraflores, en plena Guerra del Pacífico, con una dama peruana. Pero esta señora tenía muy frescas e inmediatas la sangre germana y francesa que le habían dado origen, robustecida aquélla, además, por la educación en Hamburgo. Como era hijo de oficial, a Barrios se le otorgó beca para seguir estudios en la Escuela Militar de Chile, de manera que todo le favorecía para llegar a ser miembro del ejército. Nada de esto ocurrió: Bartios no poseía espíritu militar, a despecho de lo prevenido en las disposiciones del servicio, donde se presume que ese espíritu es hereditario, y abandonó la escuela dos años después sin concluir sus estudios, para echar a las letras, donde afirmó sus reales para siempre.

Las dotes literarias que vemos en obra en sus escritos pueden ser, si se quiere, germánicas o francesas, pero también podrían ser españolas, y dentro de la Península, andaluzas, ya que el apellido Barrios corresponde en Chile,-según tradición uniforme, a una familia de origen sevillano, que está ya por cierto muy ramificada. En su trato personal, de otra parte, Barrios manifestaba afición permanente al gracejo andaluz, y en la memoria conservaba dichos españoles que oyó en sus correrías juveniles, y especialmente a los cómicos, entre quienes vivió en Iquique y en otras partes, así como mantenía también en la memoria frases, estribillos y letras de canciones oídas en zarzuelas, operetas, sainetes y otras piezas del género chico, cuya comicidad llenó sus gustos.

Quedamos en que por medio de la investigación racial poco se avanza en el conocimiento de la personalidad de Eduardo Barrios. Veamos otros caminos.

El escritor nació en el puerto de Valparaíso, en 1884, hizo estudios de humanidades en Lima, pasó en seguida a Chile y tuvo, en plena juventud, un período de vagabundeo bohemio que podemos suponer con algunos de los datos que él mismo ha proporcionado en artículos y entrevistas: interior del Perú y acaso de la hoya amazónica, provincias argentinas del norte, Bolivia, Buenos Aires... Lo curioso es que en seguida, aquietado, retorna a Chile, se dedica al trabajo oficinesco y literario, contrae matrimonio y se hace empecinadamente sedentario. Me consta, por ejemplo, que al llegar por segunda vez al poder el general Ibáñez, en 1952, a Barrios le ofreció enviarle a una embajada, y en concreto le señaló la de Montevideo como adecuada a sus gustos, así por la belleza misma de 
la ciudad como por la fama de culta y erudita que tiene aquella capital: y me consta asimismo que Barrios no aceptó la designación, haciendo valer que sus gustos no iban a las obligaciones de la vida diplomática. En sustitución, el general Ibáñez le nombró de nuevo Director General de Bibliotecas, cargo que ya le había conferido antes, en su primer gobierno (I927-3I).

-De esta manera - comentó Barrios, sin amargura--, no he vuelto a salir jamás de Chile, y me quedaré sin conocer a Europa.

Debe agregarse que a pesar de este voluntario alejamiento de los grupos intelectuales de circulación internacional, a Barrios se le ha extendido credencial que le abre paso por todas partes. Hay, desde luego, la singular gravitación que está ejerciendo su obra en los medios universitarios de los Estados Unidos. Parece que la atrevida inquisición en los motivos de la conducta humana, desarrollada en algunos de sus libros, atrae la atención primero de los catedráticos y en seguida de los alumnos, y el hecho es que no pocos aspirantes a los grados de doctor han cumplido ya requisitos con la presentación de tesis sobre Barrios, y que otros se encuentran ahora mismo trabajando el tema. Conozco personalmente el interés de los estudiantes avanzados de español en las Universidades de California, Colorado y Tulane (que funciona en Nueva Orleáns) por el estudio sistemático de Barrios. Unos me consultaron sobre la posibilidad de escribir algo sobre él, y otros, desalentados al ver que se les habían adelantado en el camino, me preguntaron si se podrían tratar, monográficamente, aspectos hasta hoy no tocados en la obra de Barrios. A mí me parece, a propósito, que no se ha estudiado eficaz y hondamente hasta ahora el aspecto del estilo, esto es, la elaboración de la forma en Barrios, considerada como instrumento de comunicación entre autor y lector, para indicar sobre todo la evolución hacia la sencillez y la transparencia, que se observa en las obras que corren entre Del naturd (1907) y $\mathrm{El}$ hermano asno (I922): pero entiendo también que estudiantes de otra lengua no sean los más aptos, a pesar de sus excelentes disposiciones, para afrontar semejante estudio. Quien lo afronte debe ser sin duda un especialista de nuestro mundo cultural.

El propio Barrios parece haber apuntado a este asunto, porque en el revelador ensayo También algo de $m^{i}$ se expresa en esta forma:

... He dicho sobre mi ideal de estilo: música y transparencia, porque con esto cumplido, las démás virtudes vienen solas. ...Porque yo desearía que al leer mis obras el lector se olvidara de que lee y reci- 
biera solo, como directas de la vida y la naturaleza, las sensaciones y las emociones de cuanto quise comunicarle. A esto tiende todo mi esfuerzo de prosista: a la transparencia, para que nada estorbe ni distraiga, y a la música, porque sin ella no hay ondas simpáticas que penetren el corazón. (Obras completas, I, p. 28).

$\mathrm{La}$ verdad es que los dos ideales son difíciles de lograr, y que la dificultad sube de punto cuando se les reúne y aparea como hace Barrios. El análisis del estilo en atención a la transparencia y a la música nos permitiría demostrar, tal vez, que las dos virtudes lograron un dinámico equilibrio en El bermano asno: que dominó la primera en El niño que enloqueció de amor, y que acaso el autor se inclinó demasiado a la segunda, esto es, al efecto musical de la prosa, en Gran señor y rajadiablos. Pero esto es ya avanzarse sobre los resultados de una pesquisa que no se ha hecho, es decir, prejuzgar. Quede el tema abierto.

Barrios es novelista de la ciudad, y no de una ciudad cualquiera, sino de la de Santiago, donde pasó la mayor parte de su vida. Es verdad que nació en Valparaíso y se educó en Lima, y que algo aventuró por los paises suramericanos vecinos, pero en sustancia las páginas de sus libros entonan una especie de cántico de amor a Santiago. Un amanecer de rosa con velos de neblina, en que se divisan mezclados los árboles del Parque Forestal y los faldeos del Cerro San Cristóbal, podemos hallar en Un perdido, fresca y nítida nota de luz matutina en medio del cuadro de la bohemia que se ha ido ennegreciendo poquito a poco, cual si fuera un hecho fatal. En su famosa novela franciscana El bermano asno la ciudad penetra, con algunos de sus rumores característicos, los espesos mutcs del claustro, y cuando éste queda a medias derribado para que allí se construyan casas, el espacio abierto establece de pronto una rara comunidad con las vistas del vecindario. La clausura ha sido violada, y el aire del mundo entra atropelladamente a los patios conventuales.

En Páginas de un pobre diablo hay la sordidez de los negocios establecidos en la primera cuadra de la calle San Diego, también mencionada en $U n$ perdido, donde además tenemos la vida algo promiscua en la cité y el ambiente sucio - material y moralmente hablando- de la oficina pública. Cuando Lucho Bernales se halla en el medio que corresponde a sus antecedentes, un palacio le recibe; y cuando, caído, va rodando 
siempre cuesta abajo, sin que nada ni nadie lo sujete en su atroz descenso, le reciben las plazas, las aceras, las cunetas, todos aquellos ásperos rincones de la urbe en que se puede lograr entrada sin pagar tarifa, ni siquiera en forma de elegante atuendo o de fresca apostura.

Barrios escribió la novela de la ciudad, y desde este punto de vista cumplió cuanto había prometido. Su revelación con El niño que enloqueció de amor produjo subidas emociones desde 1915, y la confirmación de su miga de novelista, en Un perdido, le acarreó nuevos sufragios. En años siguientes continuó labrando en la mina de su talento, y añadió Gran señor y rajadiablos y Los hombres del hombre. Pero a Barrios no le agradaba pisar siempre una misma senda, o como le decía en carta a Manuel Gálvez: "Yo necesito que ningún libro mío reande el mismo camino o siga una misma ruta". Duro mandato que cumplió hasta el final; porque, después de haberse graduado de novelista de la ciudad con aquellas obras, volvió las miradas al campo, y alli cortó la variadísima tela de Gran señor. Obvio es decir que logró cuanto se proponía. Esta es la más completa y perfecta novela campestre que se ha escrito en Chile, y une a la riqueza documental de los motivos una amplísima galería de personajes humanos, vistos en profundidad, y finalmente un bello y gallardo estilo de prosa, donde a cada paso vemos la cláusula bien aliñada, el ritmo feliz de la lengua alquitarada con ahincado esmero.

Pero no cumplió en cuanto se refiere a la narración de los días. perdidos de su juventud, los días que no fueron aprovechados ni en la elaboración de sus libros ni en memorias propiamente tales, que más de una vez le pedimos que escribiera. Y él, tan audaz en la exploración de las almas ajenas, sentíase incapaz de exponer lo propio suyo. EI hacer novelas imprimió a su pluma cierto pudor invencible, y se ha ido sin escribir los recuerdos de su vida literaria. Es verdad que en $U n$ pevidido vemos algo de la bohemia santiaguina de los medios artísticos hacia I915, y que alli figura como eje el increible Claudio de Alas; pero Barrios había visto mucho más que eso, y pudo narrarlo. De mozo, por ejemplo, según propia confesión, había recorrido media América, y estos viajes no los había hecho como turista, servido en hoteles y con dinero holgado para compensar en agrado las estrecheces de la caminata, sino, al revés, sufriendo las privaciones inherentes al origen mismo de su viaje. Era entonces un rebelde, y su rebelión contra el orden familiar le llevó a dejar su casa, para ver si le era posible hacer su vida a solas, sin deberle nada a nadie.

En coyuntura parecida, Rubén Darío decía que si no cayó fue por- 
que "Dios es bueno", y Barrios podría repetirlo. De esos azarosos comienzos, de esas pellejerías juveniles, ascendió y llegó a ciertas encumbradas alturas que difícilmente pudo imaginar cuando era un vagabundo buscavidas. Fue Ministro de Educación Pública, fue Director de la $\mathrm{Bi}$ blioteca Nacional, y habria podido ser embajador si en los comienzos de 1953, recién elegido Ibáñez por la segunda vez, hubiera deferido a la invitación que éste le hizo, según ya contamos. Y entonces se da el caso ciertamente inverosímil de que este escritor, a quien se ha traducido a seis o más lenguas, a quien se estudia en las cátedras de Estados Unidos y de otros países, sobre el cual se han escrito docenas de estudios y ensayos de aproximación crítica y de análisis estilístico y de investigación psicológica, en multitud de universidades, jamás fue por Europa, ni conoció país alguno de fuera del continente americano del Sur. ¿El buen paño en el arca se vende? Sin duda así es, por lo menos en este caso, ya que Barrios pudo llamar la atención sobre sus valores a la distancia, sin ir a exhibirlos.

Para hacer más entrañable la expresión y para comunicarse con el lector sin intermediarios, Eduardo Barrios empleó con frecuencia el diario intimo y las cartas. Nadie ignora que en El niño que enlóqueció de amor la novela está contada por el propio muchacho enamorado, en páginas de un diario intimo que oculta a las miradas de todos, y el mismo procedimiento se da en $E l$ bermano asno. Aquí es fray Lázaro quien abre el diario para ir narrando una por una las alternativas de la vesanía de fray Rufino. También consta en las anotaciones de un diario el cuento o novela corta titulada Páginas de un pobre diablo; y, finalmente, no puede olvidarse que es diario Los bombres del bombre, donde una taracea de mil detalles psicológicos muy menudos llega a componer la novela. Beatriz, la mujer, descubre este diario, que siempre debió haber quedado fuera de su vista, y uno de los momentos más dramáticos de la novela es el que sigue a ese descubrimiento. Las cartas cobran papel asimismo en esta literatura que podríamos llamar confidencial. Son cartas las que se cambian dos jóvenes frívolas para contar en ;Pobre feo! el drama del muchacho de infeliz figura que se enamora de una de ellas.

La conclusión que se obtiene es de todos sabida: Eduardo Barrios es un novelista a quien interesan más las almas, con sus complejidades, que los actos, y cuando se trata de aquellos pliegues íntimos que forman 
la persona humana, toda atención le parece poca a fin de establecer lo que cree significativo. Menos observado es cómo el autor escoge el diario de anotaciones íntimas y la carta, porque en ellos la aproximación al sujeto de estudio puede lograrse mejor, y porque también puede alcan. zarse con mayor eficacia la iluminación introspectiva. La locura de fray Rufino, en El hermano asno, no podía haberse hecho visible por medio de un diario escrito por él mismo, ya que el novelista le presenta como hombre de muy pocas luces; pero descrita por el hermano de claustro, observador e inteligente, podía resultar un toque maestro, como efectivamente lo es.

Otra confesión directa del autor importa para fijar mejor lo que venimos diciendo. Oigamos sus palabras:

No tengo predilección por ningún género determinado en literatura. Los acepto, como igualmente buenos, todos. En todo cabe algo de nosotros; y nosotros no cabemos enteros en todos ellos juntos. Además, cada una de las cosas que necesitamos comunicar exige su género. Géneros, más bien, hacen falta. De aquí mi gusto por el teatro, por el cuento, por la novela y aun por el verso, que hago a escondidas, como quien comete un secreto y delicioso pecado.

Si cultivo de preferencia la novela, es porque en ella entran todos los géneros: el episodio no es otra cosa que el cuento; el diálogo coge del teatro la palpitación viva, el calor del movimiento, y con la ventaja de hacerlo con voz queda ...; el poema, en fin, estremece la concepción, canta en el tono de la emoción enaltecida, en las sensaciones clarificadas, y en cada oportunidad, lírica, exprime su sangre azul. (También algo de mí, ibidem, p. 29).

Estas palabras nos indican, además, de paso, que no es justificada la omisión del teatro que se ha hecho al compaginar las llamadas Obras. completas, puesto que en el espíritu del escritor cada uno de sus dramas, extensos o breves, forma parte de la concepción polifacética del arte de: comunicación vital a que él declaró hallarse entregado.

Veamos ahora algo de las obras fundamentales de Eduardo Barrios, entendiendo por tales aquellas que el público ha leído con mayor entusiasmo, cual puede juzgarse por el número de sus ediciones. Una de ellas: es, desde luego, El niño que enloqueció de amor (r9r5), obra delicada, 
tierna, sutil, de plena juventud (cuando la publicó, Eduardo Barrios había recién cumplido treinta años de vida), que sigue siendo leída con embeleso.

Se comete a menudo el ertor de atribuir dimensión autobiográfica a esta novela, debido a que el propio autor ha dicho que con ella procedió a rememorar en forma literaria un episodio de su niñez. Es frecuente que los chicos imaginativos y sensibles se enamoren de mujeres de más edad; pero en la tragedia de El niño que enloqueció de amor hay mucho más que eso. Desde luego, debe tenerse en cuenta que el verbo enloquecer ha de ser entendido en su sentido recto y con todas las implicaciones biológicas pertinentes: el chico del relato pierde la razón, se vuelve loco, y cuando el novelista se inclina a considerar su caso y lo escribe, sigue loco, al cuidado de su madre y atendido por médicos que procuran diagnosticar al través de los síntomas. Bastaría esto para señalar que no es el autor el protagonista de aquella angustiosa aventura.

¿Cuál es, entonces, el contenido autobiográfico de este cuento largo o novela corta? Sólo aquel que el mismo Eduardo Barrios ha señalado: él, de chico, sintió entusiasmo apasionado por una muchacha de más años, que visitaba la casa de`su madre, y uniendo recuerdos de sus emociones de esos días y noticias de otros sucesos parecidos con aquel caudal informe $y$ vario de experiencias de que el novelista hace uso en sus. exploraciones previas a la redacción, combinó el espécimen de que trata su libro. En él, por lo demás, lo que en definitiva importa no es si la aventura la vivió Eduardo Barrios u otra persona: importa la forma de la ejecución, esto es, cómo se las arregló el autor para salir triunfante en el alarde técnico que se planteó como pie forzado, el de dar estructura de diatio íntimo a las impresiones de un niño de diez años de edad. Debe balbucir, repetir, emplear términos que no sería discreto que manejara bien todavia, y dar paso a observaciones y reflexiones infantiles, pueriles propiamente, al través de las cuales ha de reflejarse sin duda la precocidad, sin perjuicio de que se mantenga en pie, a la vista, siempre vigente, lo propio del niño, esto es, la mentalidad incipiente, la falta de cálculo y de malicia, el empecinamiento sin esperanza, los celos irracionales, etc.

Salvo momentos en los cuales el chico juzga con demasiada acritud a los mayores, el resultado es generalmente muy feliz, y el lector logra hacerse la ilusión de que aquel documento no es propiamente novela creada e inventada sino diario íntimo de un chico enamorado, enamorado hasta la locura. Al final, cuando el diario debe enterarnos ya de la 
incoherencia propiamente vesánica, el autor interviene y esboza una escena de epílogo que explica muchos pormenores de la obra.

Entre todas las novelas de Barrios, la que mayor variedad de ambientes muestra es $U n$ perdido (rgr8), vasto fresco de la vida chilena en términos geográficos tan distantes entre sí como Santiago e Iquique. Entre algunos otros temas de menor monta, cabe señalar en $U n$ perdido todos los siguiente, anotados más o menos en el mismo orden sucesivo que ocupan en el libro.

Vida de pueblo chico en Quillota, donde el hogar de los señores Vera es todo un modelo de buen entendimiento, amor y solicitud reciproca, y vida de puerto en Iquique, durante el mayor auge de la exportación de salitre. Aquí, sin embargo, deben distinguirse además otros temas especiales, que merecen atención: uno está formado por el interior de los prostíbulos, donde las damas de vivir galante nos van diciendo claramente qué puntos calzan en materia de amor, codicia, abnegación, celos, etc.; otro es la existencia de los oficiales de la guarnición, sea en la intimidad del casino, sea fuera de allí, en contacto con los cómicos y con las prostitutas. Es tal la riqueza de los pormenores explotados en esta parte, que bien podría asegurarse que es ella la mejor del libro, y una de las más vívidas de la novela chilena en su porción realista $o$, si se prefiere, naturalista.

Cuando el personaje principal, Luis Bernales, muerto su padre en Iquique, pasa a Santiago, es acogido en casa de sus abuelos paternos, y en seguida inscrito en la Escuela Militar. Las escenas ocurridas en este establecimiento son cortas en número, pero de grande elocuencia. En el hogar de sus abuelos, Luis Bernales vive como allegado sin fortuna, y más de una vez se le hace sufrir con rudeza la adversidad de su suerte. $Y$ es que $U n$ perdido es, además, novela de enredo familiar, en la cual se aprovechan muy discreta y artísticamente las desinteligencias entre la gens Vera y la gens Bernales: unos y otros se enrostran vicios, deformidades de la conducta, rarezas y estupideces que cada grupo atribuye al bajo nivel social del adversario. Luis Bernales, que por su madre es Vera, queda entre la espada y la pared, y sus abuelos Bernales y los demás de la misma familia lo humillan y lo oprimen cuanto pueden. Así y todo, estuvo Luis a punto de casarse con una prima lejana, niña rica y sin padres, de gran belleza, a quien terminó por conquistar, sin mayor esfuerzo, su hermano, ya ventajosamente colocado en la joven oficialidad de la marina de guerra.

En los capítulos que siguen vemos la vida de empleo burocrático, 
dentro de la Biblioteca Nacional (en realidad, se trata de las oficinas administrativas de la Universidad de Chile), con una pequeña galería de seres pintorescos, muy bien dibujados, y la bohemia artística de Santiago, con Braulio Azolas como centro, cuyo nómbre corresponde al seudónimo Claudio de Alas, el ser vivo que dio otigen al personaje, es decir, el colombiano Jorge Escobar Uribe.

El nudo psicológico central de la novela nos lo dan los amores de Luis Bernales y de Teresa Bórquez, los cuales se inician en la pensión de la calle San Diego, y siguen y alcanzan desastroso desenlace en la cité de la calle San Francisco. Teresa engaña a Luis con Rojas, empleado de la Biblioteca, y luego huye en compañía de una mujer de las vecindades. Se presume, por diversos antecedentes esparcidos en el texto, que las dos van a dedicarse a la prostitución. La revelación de la fuga sume a Luis Bernales en una especie de estupor dramático que no se alivia sino por medio del alcohol, y desde allí hasta el fin sólo se le ve decaer, en lento pero seguro suicidio. En la parte final aparece otra vez la bohemia de los artistas, pero no ya en el nivel de Claudio de Alas, relativamente decoroso, sino en otro mucho más bajo, plebeyo, de mal gusto. En esta última parte llama la atención, por lo bien diseñado del personaje, don Darío, que practica una alcahuetería curiosísima.

Todos estos centros de interés cobran diferente extensión. Los amores de Luis y de Teresa tienen desenlace propio, y con ellos comienza la declinación del protagonista, hasta el punto de que sus antiguos amigos de la Escuela Militar y de la guarnición de Iquique, recordándole, puedan Ilamarle "un perdido". La obra pertenece sin duda a la progenie de La educación sentimental de Flaubert, y en su personaje protagónico Eduardo Barrios ha querido, ostensiblemente, mostrar el carácter del tímido, a quien una organización psicológica muy particular deja sin defensas ante la rudeza de la vida, la cual termina por destrozarlo. Todas las veces que se divisa al personaje salir un poco de su timidez para vencer sus limitaciones, el resultado es una fracaso. La abulia hace el resto. Difícil es imaginar novela más desalentadora. El naturalismo de $U n$ perdido se afinca no sólo en escenas riesgosas, de malas costumbres y de actos viciosos, que también las hay, sino en la filosofía determinista que se vierte en algunos pasajes y que viene a resultar decisiva para juzgar de la conducta del héroe o protagonista. A este mismo Luis Bernales, cuando Teresa, su concubina, le abandona, se le presenta la oportunidad de buscarla, para hacerla regresar al nido roto; pero él la deja 
pasar y se abandona en forma fatalista a lo que ha sucedido. En su monólogo interior se dice:

Para él no quedaba sino arrastrar los días, flotar inerte, indiferente, en esta existencia en que nada gobernamos. Bien decía Blanco allá en Iquique. Nos mueven efectos determinados por causas entretejidas desde el principio de los siglos, sin que nuestra voluntad entonces para nadie interviniese. Absurdo, ley indomable y dura. Pues bien, entregarse, puesto que todo era inútil. (Un perdid $\sigma$, Segunda parte, XXVII).

Pocas líneas más adelante, cuando Luis Bernales en lugar de seguir buscando a Teresa pasa a un bar y bebe, otra forma del determinismo ya señalado aflora en su meditación:

Y ahora, pues, caminaba sin rumbo, en medio de la noche, bajo aquel cielo alto, claro y frío, entre aquellas casuchas infames, las carnes de los flancos mordidas por el hielo de agosto, y encorvada la espalda, y empañada por el aire la vista, y presa de un semiatontamiento de ebriedad, y con el espíritu inmóvil, apenas sarcástico y dispuesto a reír de esta vida indominable y absurda en la que todo viene determinado desde los siglos de los siglos para marchar a la muerte, a la muerte de los hombres, de las razas y de los mundos. (Un perdido, ibidem).

Esta filosofía determinista trae su origen de una observación cosmológica que Bernales oyó exponer, siendo muchacho, al teniente Blanco, uno de sus mejores compañeros en la guarnición de Iquique, observación en la cual Blanco por lo demás apoyaba toda una teoría metafísica y de conducta moral.

¿Recuerdas qué decía ese libro? Que la tierra es apenas una bolita de barro lanzada en el espacio infinito. $Y$ eso es, ni más ni menos. En partes tiene gotas de rocío, los mares; en otras, terroncillos, los continentes; sobre ellos hay musgo, los bosques y los campos, y bichos insignificantes, nosotros, y aun las fieras... Pues bien, Lucho, esta pelotilla de lodo ha de morir, imagínate, si es que te parece poco lo de la pequeñez. Morirá como ha muerto la Luna, como todos los astros mueren... Ya te habrán enseñado esto en el 
colegio... Y de nosotros, de nuestros hijos, de todas las generaciones, de las grandes glorias, de los renombres, nada quedará. Después, el planeta yerto se irá disgregando también con los siglos, con esos siglos tan largos para nosotros y tan cortos para la eternidad. ¿Eh? ¿Qué dices? Divirtámonos, hagamos lo que se nos antoje, conforme a los dictados del corazón. (Un perdido, Primera parte, XIX).

Este nihilismo de la conducta, basado en la concepción cosmológica de la fugacidad de la vida de la Tierra, produjo las consecuencias más dispares. El individuo que promulgaba la doctrina, teniente entonces, ascendió en la carrera, y al final del libro es informado del desastre de Luis Bernales, muestra solícito interés por él y aun expresa el deseo de verle. Todo un cuadro de la vida de su juventud está ligado al mozo que le oía absorto en Iquique.

Ha sido parte de la filosofía estética de Barrios el afrontar siempre, en cada novela, el compromiso de tratar asuntos que nada tengan que ver con los atendidos antes, personajes de otra extracción y ambientes en todo inéditos. Cumpliendo esta ley, en la novela siguiente, $E l$ bermano asno (I922), aparece evocado un convento de mínimos franciscanos. Las peripecias son de índole conventual y reflejan muy lejano el tráfago del mundo, al que los frailes se han sustraído voluntariamente. Mientras el narrador, fray Lázaro, se siente atado a la tierra y a los recuerdos de su existencia mundana, la imagen de la perfección se nos ofrece en fray Rufino:

Su mansedumbre es perfecta, y el amor es en su corazón un sol ardiente y esplendoroso, que no niega su luz ni a los pequeños ni a los abyectos.

El autor señala con prudencia, poquito a poco, a fin de que no se le acuse de proceder sin cautela en su caricatura, los extremos a que puede conducir la concepción ascética de la vida en fray Rufino. ¿Loco? No cabe duda: sólo a un loco pueden ocurrírsele todas esas exageraciones, y Barrios sigue los pasos de aquella locura con la misma puntualidad que pone el médico al diseñar el caso clínico que tiene a la vista. No condena, ni elogia; cuenta, sencillamente, cómo la vesania de fray Rufino se va haciendo incompatible con la propia santa paz que los frailes declaran haber ido a buscar entre las paredes del claustro.

En concordancia con el tema y con la elevada esfera de aspiraciones 
místicas por donde discurren los sentimientos de sus personajes, con esta obra ensayó Barrios nuevas formas de estilo. Escribió con extrema finura, con pocas imágenes, procurando hallar siempre voces simples, claras, las más adecuadas al plan de perfección ascética en que vivían sus héroes. La música y la transparencia, que ya vimos indicadas por el propio autor como sus grandes ideales en el estilo novelesco, encuentran aquí tal vez su culminación. A puñados pueden citarse las sentencias felices, las miradas agudas, los certeros epigramas, las evocaciones buidas de los paisajes del convento y de la ciudad que dormita al pie de su campanario. Y debe aceptarse, en fin, que el alarde de escribir sobre la vida conventual dificultaba no poco la tarea del autor, si éste quería introducir en su obra el esmero de un estilo vario dentro del ascetismo, y la verdad es que resultó dulce, persuasivo, hasta franciscano en el amor a todo lo creado.

Dentro de $E l$ bermano asno pueden, también, aislarse, al filo de la lectura, finas sentencias y delicados fragmentos de prosa, donde el autor alza la voz en solos de notable elocuencia. Allí también, finalmente, se nos da en forma de apólogo un pequeño poema en prosa que siempre habrá de citarse entre las páginas de antología que ha producido la prosa chilena. Dice asi:

Cuando pequeño, mi madre me conducía de la mano, me guiaba por todos los caminos. Un día partí, a estudiar lejos, varios años, y hube de valerme ya solo. Sin embargo, durante aquella separación, Señor, aún pensaba yo en mi madre como un niño; mis cartas llamábanla "mamá", "mamacita", y las suyas me acariciaban, cubrían de besos a su muchachuelo. Pasó tiempo, otros años pasaron, y la vida tornó a reunirnos. Fue allá en una ciudad del Norte, donde ciertas ambiciones me llevaron en busca de fortuna, y en la cual ella se sentía extranjera entre las gentes y las costumbres. Entonces, de repente, nos hallamos con que había llegado un camino por el cual debía conducirla yo a ella. Esa mañana trémula y dorada hubo en mi corazón una fiesta, bella de orgullo: dirigía yo a mi madre ahora; yo la imponía de cuanto era discreto y conveniente hacer, porque además de no conocer aquella tierra, parecía ignotar la marcha de los tiempos nuevos; yo, el fuerte, la guiaba, y ella, la débil y remisa, entregábase a mi saber y a mi prudencia.

Un día llega siempre, Señor, en nuestra vida, a partir del cual, como empieza el árbol a dar sombra y abrigo a sus raíces, los hijos 
comenzamos a cobijar a nuestra madre. Esa mañana trémula y dorada, siempre hay una fiesta en nuestro corazón, bella de orgullo; pero también perdemos el supremo bien de una madre que nos besa, nos cubre y nos protege cuando estamos desarmados. Desde entonces $\mathrm{mi}$ viejecita es una criatura que yo conduzco de la mano. $Y$ ahora no sé, madre, qué dicha vale más: si aquella de cuando tú me amparabas porque yo permanecía el más débil o ésta en que mi alma pone un brazo alrededor de tus hombros y te lleva como a una hija. No lo distingo, madre. Apenas veo que aquella fiesta es hoy un duelo, porque me ha dejado solo. (Obras completas, II, p. 590).

Fácil sería decir, por lo que llevamos narrado, que los personajes introvertidos se llevan la primacía en la atención del autor. El ejemplo de $U n$ perdido, cuyo personaje es un introvertido típico, de exacerbada timidez, parecía ser concluyente, sobre todo si se atiende a que el autor dedica allí no pocas páginas a contarnos lo que sabía de ese hombre. Igualmente podría decirse que es introvertido el pequeño personaje de El niño que enloqueció de amor; y hasta podría avanzarse que también lo es el protagonista de Los bombres del hombre (1950), obstinadamente empeñado en hacer dialogar a los diferentes individuos que siente habitar en su interior. Pero, en cambio, los extravertidos son muy fuertes y alcanzan notable desarrollo.

Uno de ellos, Valverde, el protagonista de Gran señor y rajadiablos (I948), ha de pasar a la historia de la novela hispanoamericana como uno de los varones mejor logrados, por la regular pulsación de su existencia, por sus alientos entre épicos y picarescos, por su vivir exaltado y algo frenético, por su denuedo, su gracia, su alegría, su exuberancia de buen tono y su desprecio de la opinión ajena. Podemos no aceptar todas sus hazañas, $y$ algunas inclusive condenarlas por antisociales; pero no podemos negar el abultado relieve de esa personalidad, que se sale de los marcos de la novela para invadir la historia y la leyenda de la vida americana, por lo menos en el ambiente campero.

También podría ser juzgado extravertido el personaje céntrico de Tamarugal (1944), observado en la pampa salitrera, donde a principios del siglo xx era preciso emplear procedimiento de gran coraje para hacer frente al trabajo. La persona a quien se le diga que en Tamarugal un seminarista sufre el conflicto de sentirse interesado por una mujer, y 
que por ello está a punto de interrumpir su carrera, puede creer, sin duda, que hay allí influencia de la famosa Pepita Jiménez, de Valera, que ha dado la vuelta al mundo traducida a no pocos idiomas. Pero no hay tal. Más serio que Valera, Barrios presenta al seminarista sólo para relevar mejor el drama de almas que se ha propuesto plantear, y en su obra, en fin, abre paso por segunda vez a las impresiones y recuerdos de la vida de la pampa salitrera. En la primera, es decir, en las escenas de vida iquiqueña que aparecen en $U n$ perdido, Barrios contó sólo lo que sabía de Iquique, importante puerto en sus dias, por donde emigraba de Chile, rumbo al resto del mundo, el salitre. En Tamarugal, en cambio, se diseña el vivir cotidiano en la oficina salitrera, esto es, en la planta que beneficia aquella sustancia. Todo ello con algo naturalista, como ha dicho uno de los más ponderados críticos del autor, Donald F. Fogelquist:

El escenario, la árida región salitrera del norte de: Chile, algunos episodios, tragedias en la vida del minero, y alguno que otro personaje, obreros o empleados de la compañía minera, recuerdan el realismo de Baldomero Lillo o Manuel Rojas. Hay, además, escenas que parecen delatar influencia de Germinal de Zola. Tal, por ejemplo, es el episodio del "chachero", minero que murió aplastado por las terribles mandíbulas de la "chancadora", máquina que molía el mineral del cual se extraía el salitre. Barrios no suprime aquí ningún detalle que pueda contribuir al efecto de horror y tragedia que él quiere producir. ("Eduardo Barrios en su etapa actual", en Revista Iberoamericana, Diciembre de I952, P. I4).

El resultado del balance sería, más bien, equilibrado. En la obra de Barrios hay extravertidos e introvertidos, $y$ en cada caso el escritor estudia a fondo el problema, lo expone con detenimiento, trata de persuadir a los lectores, y llega al final de su producción con la seguridad de que todo lo hizo bien, a conciencia, limpiamente.

Desde otra vertiente, podrían buscarse en las producciones de Barrios aquéllas en las cuales el protagonista es un héroe, propiamente tal, y aquéllas donde está a la vista el antihéroe. Personajes robustos, gozadores, animosos, que hacen de su capa un sayo, con cierta conciencia informe de lo abusivo de su conducta, pero que suelen disculparla o paliar sus inconveniencias merced a una filosofía acomodaticia, pueden ser los héroes de Tamarugal y de Gran señor y rajadiablos. En contraste, 
vemos personajes decadentes, de voluntad incompleta, claudicante o dislocada, que dan base a novelas donde se bordea la anormalidad psíquica o se entra en ella sin rebozo. El personaje, en algunos casos, puede ser un espectador indeciso, a quien el drama que contempla no toca sino tangencialmente, como vemos en El bermano asno; pero a veces cae en la vorágine, dentro de la novela, con lo cual se caracteriza como antihéroe, cual puede verse en $E l$ niño que enloqueció de amor, Un perdido, Páginas de un pobre diablo y Los hombres del bombre.

$Y^{Y}$ debe hacerse la reserva de que, instintivamente, hablando de Eduardo Barrios se llega al lenguaje privativo de la caracterología, como prueba de que son estos aspectos de la vida humana los que más han interesado al autor. Los sucesos cívicos y nacionales a que había de hacer. frente en Gran señor y rajadiablos, por ejemplo, están aludidos con vaguedad extrema; casi podría decirse que sólo con repugnancia aceptó el novelista mentarlos, cuando ya le era imposible no hacerlo. Es que el interés en él dominante era llegar a la introspección, la vista por dentro, el arqueo de los valores emotivos que rigen sobre la conducta del hombre, y el de invitar al lector a conocerse mejor a sí mismo, por el contraste que pueda hacer de lo que sabe de su propia alma y lo que se le cuenta de la ajena. Desde este punto de vista, la novela de Eduardo Barrios, es decir, el caudal de su labor, enriquece las perspectivas de los lectores, hace pensar en vagos y misteriosos baches de la conducta y plantea nuevos problemas psicológicos y morales, problemas que naturalmente el autor no resuelve $y$ ante los cuales no dictamina, pues su responsabilidad es distinta.

Su responsabilidad es ante todo del orden estético, y es notorio que Barrios a lo largo de su extensa carrera no ha querido jamás desviarla. Las censuras que mereció su novela Gran señor y rajadiablos, por ejemplo, indican con perfecta claridad cómo se plantean para él las cosas del mundo en torno. Es verdad que el protagonista abusa de su posición social, y algunas de sus hazañas son vulgares fechorias de señorito consentido, mal criado e insolente; pero no parece posible imaginar siquiera que el autor haya querido hacer en su novela otra cosa que formular el retrato de su héroe, para que la condenación - si procede - la pronuncien los demás, a quienes se informa del pro y del contra, se les mete en ambiente, se les proporcionan datos e informaciones de lo más menudo, de manera que su juicio sea probo y ecuánime. Si el escritor hubiera tenido la intención de justificar a su personaje, fácil le habría sido ocultar la fechoría, eliminar tal o cual iniquidad y revestir, en fin, a su 
gtan señor de la majestad épica que más de una vez en algunos de sus congéneres ha recaído. Lo que tiene de apasionante la lectura de esta novela es, precisamente, la forma desnuda en que van apareciendo las aventuras del personaje, sin que el autor suprima sino las que pudieran haber hecho descender el tono de la narración, que procuró siempre digno y noble.

Quienes han estudiado la obra de Barrios no han parado mientes, a lo que parece, en el carácter decididamente autobiográfico de Canción, una novela corta que se publica en Páginas de un pobre diablo y que, según todo lo hace sentir, fue compuesta no pocos años antes. Ramiro, el personaje principal de la obra, se retrata a sí mismo como el propio Barrios, y en la obra además se hace figurar a Gastón Labarca, pintor, el protagonista de Tirana ley, que en este caso viene llegando del extranjero...

Pero veamos lo autobiográfico. Primero, la descripción física:

Vestía traje y sombrero castaños, que armonizaban con el pelo, de igual color, y con las grandes pupilas atabacadas. Tenía treinta años, fuertes los hombros y aristocrático el andar. Entre flotantes bocanadas de humo blanco, fragante, la boca crespa y ardiente hablaba de placer y de dolor. Los grandes ojos, luminosos bajo las cejas firmes, miraban cálidos, a la vez íntimos y dominadores. Estaba siempre pálido, con palidez débil, alterable a la menor emoción. Eran contados sus amigos; reía sin estrépito y nunca se mostraba expansivo fuera de la intimidad. Solía pasar a menudo por inepto y sorprender luego con certeza de sus juicios. (Canción, O.C. I, PP. 194-5).

Dejando a un lado la complacencia íntima, que lleva a algunas exageraciones, el retrato es fiel para cuantos hayyan conocido en persona al escritor. Pero dentro de la misma página, para presentar a su personaje, el escritor agrega algunos datos de historia que calzan, en parte a lo menos, a su propia vida. Véase por ejemplo:

Sus padres habían muerto, siendo él un niño (el padre sí; la madre estaba viva, pero en Lima); y sus abuelos, viejos católicos de moral rancia, rígida e infanzona, quisieron hacerle sacerdote (no tal, sino militar, haciendo uso de las facilidades que le daba el ser 
hijo de un oficial de la Guerra del Pacífico); pero a él molestábale tanto la gramática latina como la teología y como el tufo de los cirios humeantes, y... (descrito el ambiente del Seminario, para no describir el de la Escuela Militar). ¡Bah! El jamás quería evocar aquel pasado que fue causa de una tiña definitiva con los suyos y de que se marchase violentamente al extranjero, sin más haber que sus veinte años, su rebeldía y su sed de amar (con riña o sin ella, todo lo demás es exacto). (Ibidem, p. 195).

Pero no termina allí todo, porque también cuenta el autor algo de lo que ocurrió en el extranjero con aquel joven díscolo. Leamos:

Por allá fue un pobre humilde y laborioso, un rico aturdido y gastador. Emprendió, en la montaña del Perú, una empresa cauchera que fracasó por exceso de honradez; y en Buenos Aires sirvió de reportero en un diario y vivió entre damas caprichosas, entre artistas y aun entre ladrones (esta última anécdota la contó expresamente Barrios algo después).

Luego pasamos al terreno sentimental y erótico, y siguen las confesiones como puede verse en este pasaje:

En todas partes amó y olvidó. Fue muy amado de las mujeres: todavía solian llegarle de lejanas tierras cartas llenas de llorón y exagerado desconsuelo, pero reveladoras de que su recuerdo, con la fatalidad de un sortilegio, dormía aún en el fondo de muchos corazones, como romántico reflejo de luna en la hondura encantada de una fuente.

¿Exceso de complacencia? Puede ser; pero no se olvide que el autor está describiendo a Ramiro, personaje ficticio a quien puede atribuirse cualquier cosa, y al trasponer algunos de sus rasgos a su propia fisonomía tenemos que rebajar y recortar más de algo. Sigamos:

Su vida espiritual, siempre intensa, tuvo frecuentes llamaradas que mucho tiempo le desorientaron. En una época le dominó la timidez, luego el orgullo y aun la vanidad. Enloqueció de dolor y de placer, tuvo grandes entusiasmos y pasmosas frialdades ... Y volvió a Chile, siempre con los ojos vueltos hacia el amor, seguro de que 
en él, nada más que en él, debemos depositar... siquiera nuestra esperanza.

Insisto en que podemos en esta imagen recortar no pocos detalles, para irla acomodando a la realidad, y siempre obtendremos, como saldo, los datos necesarios para declarar que estamos ante un excelente autorretrato en el cual si concuerdan los datos grandes y de bulto, bien pueden asimismo coincidir y calzar algunos de los menudos e íntimos.

Hace unos pocos meses se han publicado en Chile dos volúmenes de unas Obras completas de Eduardo Barrios, que en total suman poco más de mil ochenta páginas. Si hojeamos estos pliegos (y si, mejor aún, los comparamos con una bien autorizada bibliografía del escritor), pronto llegaremos a la conclusión de que no son completas, es decir, que en ellas no se ven algunas piezas cuya existencia consta por diferentes conductos. En la organización de estas Obras completas, por ejemplo, faltan todas las obras teatrales de Barrios, que constituyen una parte nada desdeñable de su labor. Es verdad que con el tiempo ha cobrado fama ante todo de novelista: pero en los años de la juventud descolló en el teatro. Una de sus primeras piczas, Mercaderes en el templo, remonta al año de rgir: otra, Papá y mamá, fue agregada en las páginas finales de $E l$ niño que enloqueció de amor, para dar más cuerpo al volumen. iAnte todo la oficina!, titulada antes Por el decoro, fue añadida igualmente en el libro miscelánico titulado $Y$ la vida sigue (r925). Las piezas principales son, sin embargo, no las ya citadas, sino Lo que niega la vida y Vivir, que dieron en su tiempo muchísimo que hablar. La primera se publicaba ya en I9 3 , a raíz de su estreno en la escena santiaguina, y la segunda quedaba lanzada al público en I9I6, una vez que el autor hubo agotado las diligencias hechas para estrenarla ... No porque la obra fuese mala desde el punto de vista escénico, sino porque es muy audaz en su formulación, y todos los actores a quienes se consultó el texto, declararon que no se atrevían con el público al exponerle en forma tan cruda y violenta el drama del amor adúltero cual allí se le plantea.

Barrios fue, además, colaborador esporádico en la redacción de varios periódicos, como La Mañana, El Mercurio, Las Ulltimas Noticias, I. N Nación, en temporadas breves, porque, según todo permite suponerlo, no era el de la improvisación cotidiana el género más vecino a sus gustos. Así y todo, es digna de atención la serie de comentarios críticos 
que publicó en Las Últimas Noticias durante unos pocos años, porque ellos le permitieron fijar su doctrina en multitud de puntos relativos al arte de componer literatura. Cosa semejante cabe decir de páginas como La saturación literarid y la fecundidad, que el autor publicó en La Nación dc Buenos Aires, diario que acogió también algunos otros de sus ensayos. En este ensayo, conforme sugiere el título, el autor se pronuncia contra la fecundidad, asentando: "No dure nuestra vida más allá de nuestra gloria", y corroborando:

... No escribamos sino cuando realmente tengamos algo que decir, y, además, cuidemos de llevar nuestra producción al público más bien alargando el camino, como alarga el buen amador el placer de su doncella. Llegar a los sesenta con una gloria mustia y caducada, equivale a andar con nuestro cadáver a cuestas.

Sea lo que fuere de esta doctrina, es la que Barrios llevó a la realidad a lo largo de su existencia. Es verdad que varios años antes de su fa1lecimiento dejó de escribir, y que, según parece, importantes proyectos suyos, postergados en horas activas, quedaron para siempre incompletos y truncos; pero su gloria estaba vigente y en pleno auge cuando, a los setenta y nueve años, se cortó su aliento vital.

Con aquellas obras escénicas y algunos ensayos y artículos literarios, podría componerse un tercer volumen de estas Obras completas, indispensable acaso para que el título escogido corresponda a la realidad.

Si miramos hacia la novela hispanoamericana en conjunto, veremos que Eduardo Barrios se caracteriza, en primer lugar, por la seguridad ejemplar con que maneja la lengua, todo ello en grado tal, que algunas de sus páginas caen en lo primoroso y en lo maestro. En segundo lugar, complace verle siempre en trance de renovación buscando ambientes poco frecuentados por sus colegas y tratando de no repetirse, de no agotar la paciencia del lector y de ir al encuentro de su curiosidad con medios elegantes. Las escenas más riesgosas de $U_{n}$ perdido no son feas, y de ninguna podría decirse que al escribirla el novelista se ha detenido en detalles salaces. Aunque reducida, de su galería novelesca puede decirse, en tercer lugar, que encierra un escogido muestrario de las existencias de importantísimos grupos sociales que se dan en todos o casi todos los 
países hispanoamericanos, con variantes geográficas en pormenores pero: no en los rasgos gruesos.

Por ello su obra ha salido, de muchos años a esta parte, del ámbito nacional, y es saludada y aplaudida en muchos otros, esto es, hasta donde alcanza el imperio invisible e impalpable de la lengua española, de la cual esa obra forma un relevante monumento.

Raúl Silva Castro

Biblioteca Nacional,

Santidgo de Chile. 